\title{
Treatment Beliefs in Patients with Mental Disorders in Psychosomatic Rehabilitation
}

\section{A Qualitative Analysis}

\author{
Rieka von der Warth¹ (D, Anne Nau, Matthias Rudolph², Matthias Stapel ${ }^{3,4}$, \\ Jürgen Bengel ${ }^{5}$, and Manuela Glattacker ${ }^{1}$ \\ ${ }^{1}$ Section of Health Care Research and Rehabilitation Research, Medical Center - University of Freiburg, Faculty of Medicine, \\ University of Freiburg, Germany \\ ${ }^{2}$ German Statutory Pension Insurance Rhineland Palatinate, Clinic for Psychosomatic Rehabilitation, Boppard-Bad Salzig, Germany \\ ${ }^{3}$ German Federal Pension Insurance, Speyer, Germany \\ ${ }^{4}$ Department of Psychology and Health, SRH - The Mobile University, Riedlingen, Germany \\ ${ }^{5}$ Section of Rehabilitation Psychology and Psychotherapy, Department of Psychology, University of Freiburg, Germany
}

\begin{abstract}
Background: The efficacy of inpatient psychosomatic rehabilitation in Germany can be considered proven. However, a significant number of patients with mental disorders remain unsatisfied with rehabilitation or being non-responders. Illness beliefs, as the core element of the Common-Sense Model of Self-Regulation (CSM), are widely known as predictors of various health outcomes. Yet, little is known about treatment beliefs as an extension of the CSM and their impact on health outcomes. Aim: As treatment beliefs differ in relation to the treatment, this study aimed to explore rehabilitation-related treatment beliefs in psychosomatic rehabilitation patients with mental disorders before inpatient admission. Thus, knowledge of the concept of rehabilitation-related treatment beliefs will be added. Methods: $N=10$ semistructured telephone interviews were conducted in September/October 2018. A purposive sampling approach was chosen based on the criteria gender, age, and diagnosis. Participants were asked about their rehabilitation expectations starting with an open narrative question. Interviews were analyzed using qualitative content analysis. Results: Participants had a mean age of 48.3 years $(S D=9.42)$; five participants were female and five male. 9 main themes with 32 subthemes as components of the rehabilitation-related treatment beliefs were identified: reasons for rehabilitation, conditions within the clinic, rehabilitation planning, organization of the rehabilitation, the content of the rehabilitation, results of the rehabilitation, concerns, expectations toward one's behavior, and contact to other patients. Limitation: Our sample was too small to analyze the data for different subgroups. Conclusion: Results show that rehabilitation-related treatment beliefs are multidimensional, addressing different aspects of psychosomatic rehabilitation.
\end{abstract}

Keywords: treatment beliefs, psychosomatic rehabilitation, common sense model of self-regulation, qualitative methods

\section{Objective}

Psychosomatic inpatient rehabilitation is a significant part of the healthcare system in Germany, playing the second most important role within the treatment of individuals with mental disorders. Based on the International Classification of Functioning, Disability, and Health (ICF), psychosomatic rehabilitation follows a holistic and person-centered view of the patient, addressing both mental and somatic disorders with a psychotherapeutic approach (Linden, 2014). The average inpatient treatment duration is 38 days in psychosomatic rehabilitation (Köllner, 2014). The most common disorders found in inpatient rehabilitation are mood disorders, anxiety disorders, adjustment disorders, somatoform disorders, and personality disorders (Linden, 2014), while an acute psychosis or acute suicidality is defined as a contraindication for psychosomatic rehabilitation (Paar \& Grohmann, 2008). In contrast to acute psychiatric care, psychosomatic rehabilitation treats mental disorders and somatic disorders with a chronic course with an average of 5-7 years (Nübling et al., 2019), no acute crisis or psychological instability, and patients with an occupational disability of at least 6 weeks within the last 12 months (von Wahlert \& Mestel, 2008). However, psychosomatic rehabilitations' treatment is not mainly based on diagnoses and its objective does not follow a curative approach but a rehabilitative one by, for example, lessen the consequences of illness, strengthening coping styles, and restoring the capacity for work and 
social competence (Paar \& Grohmann, 2008; von Wahlert \& Mestel, 2008). For this purpose, interventions in the context of psychosomatic rehabilitation include single- or groupbased psychotherapy, patient education, physical health, and interventions to support work reintegration, for example, occupational therapy, offered by psychologists or psychotherapists, medical doctors, sport therapists, occupational therapists, and social workers. In conclusion, inpatient psychosomatic rehabilitation aims at restoring participation in social and vocational life, applying a multimodal and multiprofessional approach based on the ICF (Linden, 2014).

The efficacy of psychosomatic rehabilitation can be considered proven for the German rehabilitation system. In a meta-analysis including more than 65 studies an adjusted treatment efficacy of $d=0.51$ was found (Steffanowski et al., 2007). Furthermore, the majority of patients are satisfied with their psychosomatic rehabilitation treatment (Grothaus et al., 2014). However, a significant number of patients can be considered unsatisfied with rehabilitation, and about $20-30 \%$ of all patients are non-responders, with up to $10 \%$ of all patients even experiencing a decline in health (Reuter et al., 2014).

Thus, detecting predictors for the effectiveness of psychosomatic rehabilitation as well as for patient satisfaction is of relevance. Previous research found that age, duration of symptoms, psychological burden at the end of treatment, treatment-related self-efficacy, and concerns were related to patient satisfaction in psychosomatic rehabilitation (Richter et al., 2010), while high symptom burden, chronic disease course, somatic syndromes, personality disorders, early non-response, and insufficient therapeutic alliance predict a negative treatment outcome (Reuter et al., 2014). Furthermore, a body of research revealed the relevance of illness beliefs as important predictors of various health outcomes such as treatment adherence or quality of life for different populations (e.g., somatic and psychiatric) and different health care settings (e.g., inpatient rehabilitation; Glattacker \& Heyduck, 2016; Glattacker et al., 2013a, 2013b; Tiggelman et al., 2014; van Erp et al., 2017). Illness beliefs, which comprise representations of the label and symptoms of the illness, as well as of the cause, consequences, controllability, and course of the illness (Leventhal et al., 2003), are a core element of the Common Sense Model of Self-Regulation (CSM; Hagger et al., 2017). The CSM states that patients develop individual ideas and representations (illness beliefs) when they are facing a health threat. Those presentations lead to coping procedures affecting the health outcome (Glattacker \& Heyduck, 2016; Hagger et al., 2017; Leventhal et al., 2003).

Horne (1999) expanded the CSM by adding treatment beliefs to the model, resulting in a stronger focus on the interaction between illness beliefs and treatment beliefs.
In accordance with illness beliefs, treatment beliefs as well affect coping procedures and health outcomes (Horne, 1999). In the context of drug-based treatment, perceived necessity and concerns were found to be the core components of treatment beliefs (Horne et al., 1999). In a metaanalysis including 94 studies, Horne et al. (2013) found that higher perceptions of necessity and fewer concerns were associated with higher adherence in individuals using medicine. Furthermore, in patients with asthma, treatment beliefs explained more variance of adherence in addition to illness beliefs than illness beliefs alone (Horne \& Weinman, 2002). Even though treatment beliefs regarding non-drug based treatment, such as psychotherapy, have been studied less, some studies indicate the importance of treatment beliefs also in non-drug based treatment settings such as inpatient rehabilitation (Glattacker et al., 2013a, 2013b) or in psychotherapy, where the interaction between treatment beliefs - operationalized through expectations toward the therapy - and the actual experiences was found to be a major influence on the health outcome (Barrett et al., 2008). Furthermore, perceptions about the agreement on therapy goals and therapists' expertise were found to be relevant factors of treatment beliefs in psychotherapy (Barrett et al., 2008). Within the rehabilitation setting, a study using focus groups found that treatment beliefs of patients comprised expectations toward the process of the rehabilitation, the results of the rehabilitation, and rehabilitation-related concerns (Heyduck et al., 2011).

Even though treatment beliefs can be operationalized in various ways, expectations regarding illness and treatment outcomes are an inherent part of illness beliefs (Leventhal et al., 2003). Furthermore, Hagger and Orbell (2021) stated that treatment beliefs are similar to expectancies described in social cognition approaches, leading to coping behavior. In a recent integrative model of expectations in patients undergoing medical treatment, Laferton et al. (2017) hypothesized, based on different theories such as the CSM and the Social Learning and Social Cognitive Theories (Bandura, 1986; Maddux, 1999; Schwarzer, 1994), that health outcomes are influenced, among other things, by expectations about a patient's illness- and treatment-related behavior and about the treatment itself. Within the framework of that model, expectations are operationalized as future-directed beliefs that focus on the incidence or nonincidence of a health outcome (Laferton et al., 2017).

The concept of treatment beliefs differs in relation to the treatment under consideration and little is known about the treatment beliefs of patients within psychosomatic rehabilitation. Thus, this study aimed to explore treatment beliefs, operationalized as expectations, in patients with mental disorders in psychosomatic rehabilitation before inpatient admission. Therefore, knowledge of the domains 
of treatment beliefs in non-drug-based therapy will be added. Prospectively, the results will be used to develop a CSM-based questionnaire assessing rehabilitation-related treatment beliefs in psychosomatic rehabilitation.

\section{Methods}

This exploratory qualitative study with patients in psychosomatic rehabilitation before inpatient admission was conducted at the Medical Center - University of Freiburg. Ethical approval was granted by the Ethics Committee at the University of Freiburg (Approval Number: 231/18) and was registered in the German Clinical Trial Register (DRKSO0014830). Results are reported using the Consolidated criteria for reporting qualitative research (COREQ) checklist (Tong et al., 2007).

\section{Study Design}

Participants were recruited at a psychosomatic inpatient clinic in Rhineland-Palatinate, Germany, in September and October 2018, before inpatient admission. An on-site study coordinator contacted all persons registered for psychosomatic treatment asking for participation via mail. A purposive sampling approach was chosen to guarantee a heterogeneous sample. Thus, participants were included in the study in an iterative process based on gender, age, and diagnosis (ICD-10-GM Codes). Participation was voluntary and had no consequences for treatment. Participants were supplied with written information and were asked to give written informed consent. Only if informed consent was given, contact details of the rehabilitation patients were passed on to the researchers. Due to the study design, the researcher and patient were unknown to each other at the beginning of the interview. Participants had no personal information about the interviewer who conducted the interviews but knew a scientist being in charge of the project would call them.

Using a semi-structured guideline, telephone interviews were conducted, assessing the rehabilitation-related treatment beliefs of participants before inpatient admission (Table 1). Semi-structured interviews allow participants to talk openly about their expectations toward rehabilitation and still be guided thematically. Anne Nau, Jürgen Bengel, and Manuela Glattacker developed the guideline based on existing literature on treatment beliefs (Artzt et al., 2014; Bystritsky et al., 2005; Deck, 2006; Dima et al., 2015; Faller et al., 2008; Hafen et al., 2001; Manber et al., 2003; Muthny et al., 2006) and the researchers' expertise. After an introduction of the researcher and the study, the interview started with an open narrative question about the
Table 1. Interview guideline

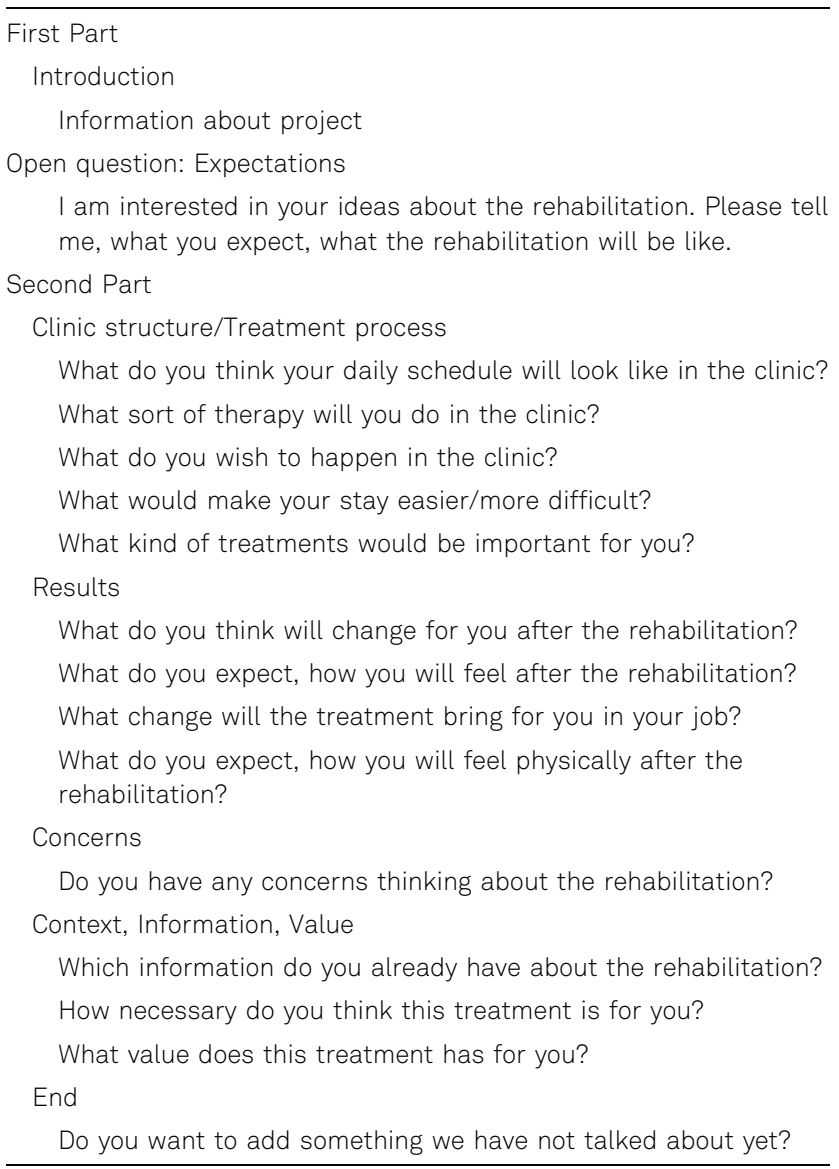

participants' expectations and ideas toward psychosomatic rehabilitation. In the second part of the guideline, participants were further asked about their expectations toward the clinic structure, rehabilitation process, expected results, and concerns. The specific topics in the second part were chosen based on the existing literature but were only addressed if the participant had difficulties verbalizing their expectations in order to minimize bias. However, topics were addressed by asking open questions and were not named toward participants as they were used only to structure the interview guideline. Expectations were operationalized as proposed by Laferton et al. (2017). Furthermore, ideas about the participants' perceived necessity of rehabilitation, the initiative for the rehabilitation, and knowledge about the rehabilitation were explored. The existing knowledge about the rehabilitation was assessed during the interviews as a possible influencing factor for treatment beliefs.

Telephone interviews were held with $N=10$ future psychosomatic rehabilitation patients in September/ October 2018 by Anne Nau. We chose to conduct $N=10$ semi-structured interviews based on the researchers' considerations, that the sample size is a) sufficient to reach data saturation and b) feasible and analyzable with available 
resources. An analysis by Guest et al. (2006) supports this approach by concluding that most themes emerge after six to twelve interviews. The interviews were digitally recorded and transcribed verbatim by an external service provider. The transcripts were pseudonymized and given a consecutive ID-Number from 1 to 10 . Following the interview, participants were asked to provide sociodemographic data such as age, gender, etc., and symptom duration. As interviews were held in the German language, participant's quotations to illustrate the finding were translated to English by the authors of this article.

\section{Data Analysis}

Data analysis followed a content analysis strategy based on the content analysis by Mayring (2000). First, an initial coding system was developed based on the themes from the interview guidelines (clinic structure; treatment process; results; concerns; context; information; value). Anne Nau and Rieka von der Warth then analyzed the first three interviews independently, using the initial coding system and taking notes if necessary. The results were discussed by Anne Nau and Rieka von der Warth, adapting the coding system to the findings by developing new main themes and subthemes. The process was repeated twice before drafting the final coding system. R. von der Warth then coded the remaining interviews in groups of three to four using the final coding system, adapting the coding system to the findings if necessary. The results were presented to and discussed at different stages of the data analysis with M. Glattacker to ensure intersubjective comprehensibility. The entire coding scheme with coding rules can be found in Electronic Supplementary Material, ESM 1. Data management was done using MAXQDA 18 (VERBI Software, 2017).

\section{Researcher Characteristics}

R. von der Warth and A. Nau are both female researchers in the field of health services and rehabilitation research. They both hold master's degrees in psychology and have experience with interviewing and qualitative analysis. M. Glattacker is a trained psychologist and postdoctoral researcher in the field of health services and rehabilitation research. Previous studies of M. Glattacker focussed on the CSM and treatment beliefs.

\section{Results}

\section{Participants}

Of all persons contacted, $42 \%(N=10)$ were willing to participate and were therefore interviewed before inpatient admission. Reasons for non-participation are not known. The interviews lasted between 14 and $40 \mathrm{~min}$, with an average of $27 \mathrm{~min}$. Five interviewees were female and five were male. The interviewees had an average age of 48.3 years with a minimum of 30 years and a maximum of 64 years. Diagnoses showed broad variations on the day of admission in the clinic as diagnosed by the therapists within the clinic. One participant stated to suffer from the indicated diagnosis for less than a year, three participants for about 1-2 years, and three participants suffered from about 6-10 years, respectively. Two participants stated they suffered for more than 10 years from their reported mental disorder. Three participants had been in psychosomatic rehabilitation before. One further interviewee said they knew a lot about rehabilitation in general from their son, who was a patient in a rehabilitation clinic. Three interviewees said they only got little information about the treatment from the clinic itself. See Table 2 for further information.

\section{Rehabilitation-Related Treatment Beliefs}

In total, 9 main themes were found: reasons for rehabilitation, conditions within the clinic, rehabilitation planning, organization of the rehabilitation, content of the rehabilitation, results of the rehabilitation, concerns, expectations toward one's own behavior, contact with other patients. Within the main themes, 32 subthemes were identified as components of the rehabilitation-related treatment beliefs. All themes can be seen in Table 3 (see ESM 1 for the coding scheme).

\section{Reasons for Rehabilitation}

All study participants reported individual reasons for the rehabilitation. Some reported their diagnosis or specific symptoms as a reason for rehabilitation. Others expressed concrete negative effects on their daily life such as negative developments for example, at work because of a lack of concentration or inner restlessness.

“And yes, and the result was, that I almost couldn't sleep anymore, that I couldn't fall asleep and then would stay awake all night long and yes, that affected my general state. I'm not able to cope anymore." (ID 10)

\section{Conditions Within the Clinic}

Study participants had various expectations of the conditions within the clinic, with the subthemes: rules, staff, food, room, and surroundings. Expectations concerning the staff in the rehabilitation clinic were mentioned mostly with a focus on the perceived need of one person who will serve as a contact person during the whole stay at the rehabilitation clinic. Interviewees wanted to be taken seriously by their therapist and needed to feel they could trust them, 
Table 2. Sociodemographic data of participants

\begin{tabular}{|c|c|c|}
\hline & Mean & Min-Max \\
\hline \multirow[t]{2}{*}{ Age (= years) } & 48.3 & $30-64$ \\
\hline & $N$ & $(\%)$ \\
\hline Sex (= female) & 5 & 50 \\
\hline German as first language (= yes) & 9 & 90 \\
\hline \multicolumn{3}{|l|}{ Marital status } \\
\hline Married & 6 & 66.7 \\
\hline Divorced & 3 & 33.3 \\
\hline \multicolumn{3}{|l|}{ School education level } \\
\hline Secondary general school (Hauptschule) & 4 & 44.4 \\
\hline Intermediate school (Realschule) & 3 & 33.3 \\
\hline Grammar school (Gymnasium) & 2 & 22.2 \\
\hline \multicolumn{3}{|l|}{ Employment status } \\
\hline Employed & 6 & 66.7 \\
\hline No, homemaker & 2 & 22.2 \\
\hline No, unemployed & 1 & 11.1 \\
\hline \multicolumn{3}{|l|}{ Main diagnoses (ICD-10-GM-Code) } \\
\hline F30-F39 Mood [affective] disorders & 5 & 50 \\
\hline F40-F48 Neurotic, stress-related and somatoform disorders & 4 & 40 \\
\hline F50-F59 Behavioral syndromes associated with physiological disturbances and physical factors & 1 & 10 \\
\hline \multicolumn{3}{|l|}{ Duration of illness } \\
\hline$<1$ year & 1 & 11.1 \\
\hline $1-2$ years & 3 & 33.3 \\
\hline $6-10$ years & 3 & 33.3 \\
\hline$>10$ years & 2 & 22.2 \\
\hline Application for disability pension (= yes) & 2 & 22.2 \\
\hline
\end{tabular}

which they believed would be the case if they were wellqualified.

\begin{abstract}
"And the other thing that would be good for me, if I really have someone, a therapist, were I notice, I mean, where I don't need to be afraid or, for me or I don't need to have the feeling that I'm somehow ridiculous." (ID 9)
\end{abstract}

Furthermore, interviewees said single rooms were important to them as they would feel disturbed in their privacy if they had to share a room. The food within the clinic was not expected to be great but eatable ("not like in a hospital").

\section{Rehabilitation Planning}

Rehabilitation planning had two subthemes with study participants strongly focusing on getting individualized therapy. Some interviewees mentioned the schedule should react to their well-being throughout their stay, especially when they would struggle during their therapy. Also, participants wanted to participate in their therapy planning from the beginning.
"What's important for me... when the number of treatments when I notice, that's too much for me, I can't handle that. .. they need to react to that; that they are not holding on to the fixed plan..." (ID 9)

\section{Organization of the Rehabilitation}

Study participants had specific expectations toward the organizational structure of their therapy during their stay with subthemes addressing the schedule during and after treatment. A fixed schedule seemed important. However, that fixed schedule was expected to be not too tight but to have time planned free of treatment. This spare time, according to the interviewees, would be used to re-think the last treatments and to process the new findings.

"Yes, to process that somehow. When the day is fully packed, I think, then you cannot take too much home from it, when there is not a little time to process that somehow." (ID 2)

\section{Content of the Rehabilitation}

The main theme "content of the therapy" could be divided into seven subthemes: relaxing treatments, relaxing techniques, activating treatments, treatments by drugs, 
Table 3. Main themes and subthemes as components of the treatment beliefs

\begin{tabular}{|c|c|}
\hline Main themes & Subthemes \\
\hline \multicolumn{2}{|l|}{ Reasons for treatment } \\
\hline \multirow[t]{5}{*}{ Conditions within the clinic } & Rules \\
\hline & Staff \\
\hline & Food \\
\hline & Room \\
\hline & Surroundings \\
\hline \multirow[t]{2}{*}{ Rehabilitation planning } & Individualized therapy \\
\hline & Participation in planning \\
\hline \multirow[t]{2}{*}{ Organization of the rehabilitation } & Schedule \\
\hline & After treatment \\
\hline \multirow[t]{7}{*}{ Content of the rehabilitations } & Relaxing treatments \\
\hline & Relaxing techniques \\
\hline & Activating treatments \\
\hline & Treatment by drugs \\
\hline & Psychotherapy \\
\hline & Psychoeducation \\
\hline & Holistic treatment \\
\hline \multirow[t]{8}{*}{ Results of the rehabilitations } & Transfer into daily life \\
\hline & Finding the old me \\
\hline & Quality of life \\
\hline & Vocational participation \\
\hline & Social participation \\
\hline & Coping strategies \\
\hline & Psychological symptom reduction \\
\hline & Physical symptom reduction \\
\hline \multirow[t]{5}{*}{ Concerns } & Misjudgment by therapist \\
\hline & Negative reactions by others \\
\hline & Data leak \\
\hline & Not able to manage rehab \\
\hline & Homesickness \\
\hline \multicolumn{2}{|c|}{ Expectations toward own behavior } \\
\hline \multicolumn{2}{|l|}{ Contact to other patients } \\
\hline
\end{tabular}

psychotherapy, psychoeducation, and holistic treatment. Activating treatment and psychotherapy seemed to be the most important themes for study participants. For activating treatment any kind of sports was found to be relevant. However, activating treatments such as art therapy or gardening was seen critical by most interviewees.

"I don't know, I'm someone who likes to do sports, even though I sometimes lack the willpower, but in general I like to do sports. And there I hope they offer great choices, because I always think, that a healthy body means a healthy soul and vice versa." (ID 1)

Interviewees had high expectations for psychotherapy. However, in most interviews, it could not be distinguished between the expectations toward individual and group psychotherapy, as participants just talked about psychotherapy in general. If a distinction could be made, the participants wished to have individual psychotherapy, arguing that group therapy would be too superficial. Some participants argued they would be afraid to speak about themselves in a group.

"Exactly, in a big group it's always hard. There it's never about...it's all so superficial, everything so abstract, yes. And then that's not...it's lost time. So I think it's just a waste of time. Yes, in small groups it's always more...more effective." (ID 7)

\section{Results of the Rehabilitation}

Results of the rehabilitation had eight subthemes including transfer into daily life, finding the "old me", quality of life, vocational participation, social participation, coping with illness, psychological symptom reduction, and physical symptom reduction. Relating to the reduction of symptoms both psychological and physical - study participants expected to be more healthy, athletic, and more selfconfident after rehabilitation. Furthermore, weight reduction was a dominant topic.

"Earlier this year, when I was in a bad mood, I lost a lot of weight, and then later with the drugs I gained it again, but I gained a lot more than I lost. And yes, maybe I can find like a good balance, the golden mean, so that I can say: Yes, I'm feeling good again." (ID 2)

Apart from the reduction of psychological and physical symptoms, participants mainly expected to have a change in their work life. Either they expected to be able to work after the therapy or to get a disability pension afterwards.

"Let's say, when I get back home healthy, physically and psychologically, then I know I can be involved and active at work again. I already planned a few things for the day after the rehabilitation for work." (ID 1)

\section{Concerns}

Study participants also had concerns regarding the rehabilitation with the subthemes misjudgment by therapist, negative reactions by others, data leaks, not able to manage rehabilitation, and homesickness. Not being able to manage the rehabilitation was described as the fear of being overstrained by the treatment or be even more exhausted after the rehabilitation.

"...sometimes I fear, when there will be a lot going on, if I'll be able to get through all this." (ID 3) 


\section{Expectations Toward One's Own Behavior}

Study participants had not only expectations toward the clinic and the rehabilitation treatment but also themselves. Interviewees said they expected to be open-minded about the rehabilitation and would at least try all kinds of treatments offered. Working actively toward getting better was considered important.
"When you register for rehabilitation, that's usually something voluntary. So I think you should go there and say: 'Yes, I'm here now and I'll take part in every- thing and I'm trying to get better'." (ID 2)

\section{Contact to Other Patients}

Study participants had different expectations concerning the contact with other patients. Some interviewees said that contact with others would help them find new solutions to their problems and give them new perspectives. Having contact with others would also help them feel comfortable at the clinic.

"I do hope that you can have conversations, let's say, with like-minded people, that I can see: Everybody has their burdens." (ID 3)

Other interviewees, however, wanted to avoid contact with other rehabilitation patients as they feared getting dragged down by the stories and feel even worse afterwards. Some interviewees said they would feel ashamed to talk about their problems to other patients.

"With all these strangers around me... I don't like to be around people I don't know in general. When I sit across them or whatever, then... Yes, would be weird to me, I can't describe that properly, but it's a bit like being ashamed." (ID 9)

\section{Discussion}

We conducted a qualitative study exploring the rehabilitation-related treatment beliefs of psychosomatic rehabilitation patients before the start of rehabilitation. For this purpose, 10 telephone interviews with patients were conducted, in which they were asked to describe their expectations toward rehabilitation. After a qualitative content analysis, 9 main themes with 32 subthemes emerged, including reasons for rehabilitation, conditions within the clinic, therapy planning, organization of rehabilitation, content of the rehabilitation, results of the rehabilitation, concerns, expectations toward one's own behavior, and contact to other patients.
The results show that the rehabilitation-related treatment beliefs in psychosomatic rehabilitation are multidimensional, addressing different aspects of the rehabilitation such as the overall organization and specific contents. In accordance with other studies, rehabilitation patients had expectations about therapy planning, organization, and results. Glattacker et al. (2009) developed a generic questionnaire assessing rehabilitation-related treatment beliefs based on the CSM. They generated items regarding the process of the rehabilitation, the outcome of the rehabilitation, and rehabilitation-related concerns. Most items on this questionnaire were mentioned by participants in our interviews as well, such as the need for a dedicated contact person (process expectation) or the reduction of psychological and physical symptoms (outcome expectation; Glattacker et al., 2009).

Perceived necessity was found to be one of two central components of treatment beliefs within the context of medical treatment (Horne, 1999), and was shown to have a significant relationship with adherence to prescribed medicine in a meta-analysis (Horne et al., 2013). In the narrow sense, this domain was not mentioned explicitly within our interviews. However, different expectations toward the results of the rehabilitation, such as the general expectation of being physically fit after the rehabilitation, implicitly contain aspects of perceived necessity even if not displayed by a specific interview code. The second central component of treatment beliefs as stated by Horne (1999) is the perceived concerns about the negative effects of the treatment. Participants in our study were predominantly concerned about not being able to manage rehabilitation and to be even more exhausted afterwards which could be defined as specific concerns about negative effects. However, compared to previous studies, participants reported only a few concerns (Heyduck et al., 2011; Muthny et al., 2006).

Leventhal et al. (2003) stated that coping procedures, analogous to illness beliefs, can also be classified into five domains: symptomatic side effects, timelines, causal routes of action, consequences, and control expectations of a coping strategy. On a content level, the findings of our study fit these domains. Thus, participants had ideas about the results of the rehabilitation (consequences) and concerns about, for example, not being able to manage rehabilitation or get misjudged by the therapist (side effects). Further, participants not only agreed to take part in the rehabilitation (causal routes of action) but also wanted to have a specific choice by taking part in the rehabilitation planning.

The patient's beliefs about their role were important within this study, generally expressing a need for autonomy. Under the main theme "rehabilitation planning" participants expected to be involved in the therapy planning 
and expressed the need to have a schedule that was at least to some degree individualized. Furthermore, interviewees considered it important to be open-minded about the rehabilitation treatment and to be actively involved to achieve treatment outcomes. Within the Framework for Patients and Family Engagement in Health and Health Care (Carman et al., 2013), describing the degree of active partnership between patients and health professionals, patients' beliefs about their role within the therapy is crucial for patient engagement. Higher engagement is defined by shared decision-making with the patient defining the agenda together with the health professionals (Carman et al., 2013). Research shows that patients being active in their health care and requesting shared decision-making have better health outcomes and care experiences (Blumenthal-Barby, 2017; Hibbard \& Greene, 2013) also within the rehabilitation setting (Lequerica et al., 2009). Therefore, perceptions about their role seem to be a relevant domain for the operationalization of rehabilitation-related treatment beliefs.

In general, the findings underline the proposed integrative model of expectations in patients undergoing medical treatment (Laferton et al., 2017). The themes found in this study seem to match the factors within the model. For example, participants had beliefs about the treatment itself, concerning the treatment outcome (e.g., "Transfer into daily life"), the structure of the treatment (e.g., "Rules" and "Staff" in the clinic), and process of the treatment (e.g., "Schedule"). Furthermore, as described above, participants expected to have personal control over the therapy. Laferton et al. (2017) included the concept of self-efficacy. It is yet unclear how our findings in this study concerning the expected involvement of patients in the therapy correlate with the concept of self-efficacy. However, one can argue that participants would not expect to take an active role in the treatment themselves if they did not expect their behavior to lead to a better treatment and health outcome. Therefore, a correlation with self-efficacy might be hypothesized.

\section{Strengths and Limitations}

To our knowledge, this is the first study exploring rehabilitation-related treatment beliefs of patients in psychosomatic rehabilitation. As we analyzed rehabilitation-related treatment beliefs of psychosomatic rehabilitation before admission into the clinic, the results are not biased by the concrete experiences of the patients during their actual rehabilitation. However, it must be considered that rehabilitation-related treatment beliefs are always influenced by the patients' biographic context such as earlier experiences with rehabilitation, rehabilitation-related interactions with family members, or physicians or other contextual factors (Leventhal et al., 2003; Yardley et al., 2001).
Even though we assessed treatment beliefs via expectations, a conceptual differentiation toward other constructs is difficult. For instance, it is not clear, if participants expressed predictive expectations as proposed by Laferton et al. (2017) or values expectations about the rehabilitation. Indeed, value expectations in the form of fantasies or wishes were found to have a negative effect on health outcomes (Oettingen, 2012). It is particularly difficult to distinguish between predictive and value expectations as they are not delineated in common usage. Thus, in the context of this analysis, expectations, wishes, and requests are used in the same context. Future research should focus on this distinction.

Although the purposive sampling approach was successful and a heterogenic sample was reached, a selection bias cannot be precluded as only $42 \%$ of all persons contacted were willing to participate. As participants were contacted before their admission, it is possible that only those patients gave their informed consent who were motivated and had thought well about the rehabilitation before. Thus, it might not be possible to transfer the results to a broader population, as non-participants might have different treatment beliefs. Furthermore, the sample was too small to analyze the data for different subgroups, for example, gender, previous rehabilitation experience, or diagnosis. Participants with various diagnoses, representing the broad field of inpatient psychosomatic rehabilitation in Germany (Linden, 2014), were included in this study. However, treatment within psychosomatic rehabilitation is not only diagnosesbased but more importantly ICF-based and targets the "limitations in capacity" and "restriction of participation" in patients (Linden, 2014, p. 207). Thus, all types of mental illness are treated within psychosomatic rehabilitation (Linden, 2014).

Furthermore, due to the predetermined sample size data saturation cannot be discussed. Even though a sample size of $N=10$ is sufficient according to some authors (Guest et al., 2006), other authors recommend an initial sample size of $N=10$ before including more participants in an iterative process until no new themes emerge (Francis et al., 2010). Additionally, the prompting of themes in the second part of the interview might have limited answers of participants. Themes were not named within the interview but related open questions were asked. However, the results show that themes beyond the interview guideline emerged.

\section{Conclusion and Implications for Future Research}

The rehabilitation-related treatment beliefs in psychosomatic patients with mental disorders before treatment admission were explored. Rehabilitation-related treatment beliefs are multidimensional, comprising 9 main themes 
and 32 subthemes. The expectation of autonomy and shared decision-making as part of the treatment beliefs was found across several themes and therefore seems relevant. Thus, new domains were added to the concept of treatment beliefs in regards to a specific treatment as demanded by Hagger and Orbell (2021).

However, more research is needed to validate these explorative findings. Thus, based on these results, a questionnaire assessing the rehabilitation-related treatment beliefs will be developed and tested in a larger psychosomatic sample. In contrast to previous instruments assessing expectation toward rehabilitation, the developed questionnaire will be based on the CSM and will follow an indication-specific operationalization.

Based on the newly developed questionnaire, a more systematic assessment of rehabilitation-related treatment beliefs might be possible. Furthermore, such a questionnaire might be used to investigate the impact of treatment beliefs on the health outcome in psychosomatic rehabilitation. Once the impact of treatment beliefs on rehabilitation outcomes is observed, maladaptive rehabilitation-related treatment beliefs might be detected and changed within a specific, CSM-based, psychosomatic intervention. Interventions aiming to change illness perception have been shown to yield promising results in the context of other indications (Glattacker et al., 2012; Goulding et al., 2010).

\section{Electronic Supplementary Materials}

The electronic supplementary material is available with the online version of the article at https://doi.org/ $10.1027 / 2512-8442 / \mathrm{a} 000087$

ESM 1. The table shows a detailed overview of the coding themes and coding rules.

\section{References}

Artzt, M. L., Pohontsch, N. J., \& Meyer, T. (2014). Vorstellungen von Rehabilitandinnen und Rehabilitanden über ihren Rehabilitationsaufenthalt [Patients' perceptions of their rehabilitation stay]. Physikalische Medizin, Rehabilitationsmedizin, Kurortmedizin, 24(2), 75-81. https://doi.org/10.1055/s-0033-1361108

Bandura, A. (1986). Social foundations of thought and action: A social cognitive theory. Prentice-Hall.

Barrett, M. S., Chua, W.-J., Crits-Christoph, P., Gibbons, M. B., Casiano, D., \& Thompson, D. (2008). Early withdrawal from mental health treamtent: implication for psychotherapy practice. psychotherapy: Theory, research, practice. Training, 45(2), 247-267.

Blumenthal-Barby, J. S. (2017). "That's the doctor's job“: Overcoming patient reluctance to be involved in medical decision making. Patient Education and Counseling, 100(1), 14-17. https://doi.org/10.1016/j.pec.2016.07.010
Bystritsky, A., Wagner, A. W., Russo, J. E., Stein, M. B., Sherbourne, C. D., Craske, M. G., \& Roy-Byrne, P. P. (2005). Assessment of beliefs about psychotropic medication and psychotherapy: Development of a measure for patients with anxiety disorders. General Hospital Psychiatry, 27(5), 313-318. https://doi.org/ 10.1016/j.genhosppsych.2005.05.005

Carman, K. L., Dardess, P., Maurer, M., Sofaer, S., Adams, K., Bechtel, C., \& Sweeney, J. (2013). Patient and family engagement: A framework for understanding the elements and developing interventions and policies. Health Affairs, 32(2), 223-231. https://doi.org/10.1377/hlthaff.2012.1133

Deck, R. (2006). Entwicklung und Validierung einer Kurzform des Fragebogens zu reha-bezogenen Erwartungen und Motivationen (FREM-8) [Development and validation of a short form of a patient questionnaire for assessing rehabilitational expectations and motivations (FREM-8)]. Zeitschrift für Medizinische Psychologie, 15(4), 175-183.

Dima, A., Lewith, G. T., Little, P., Moss-Morris, R., Foster, N. E., Hankins, M., Surtees, G., \& Bishop, F. L. (2015). Patients' treatment beliefs in low back pain: Development and validation of a questionnaire in primary care. Pain, 156(8), 1489-1500. https://doi.org/10.1097/j.pain.0000000000000193

Faller, H., Vogel, H., \& Meng, K. (2008). FEZ: Fragebogen zu Erwartungen und Zielen von Rehabilitanden [FEZ: Questionnaire on Expectations and goals of rehabilitants]. In J. Bengel, M. Wirtz, \& C. Zwingmann (Eds.), Diagnostische Verfahren in der Rehabilitation (pp. 87-89). Hogrefe.

Francis, J. J., Johnston, M., Robertson, C., Glidewell, L., Entwistle, V., Eccles, M. P., \& Grimshaw, J. M. (2010). What is an adequate sample size? Operationalising data saturation for theory-based interview studies. Psychology \& Health, 25(10), 1229-1245. https://doi.org/10.1080/08870440903194015

Glattacker, M., \& Heyduck, K. (2016). Das Common SenseSelbstregulationsmodell [The common sense model of selfregulation]. Klinische Pflegeforschung, 2, 34-37.

Glattacker, M., Heyduck, K., \& Meffert, C. (2009). Entwicklung eines Fragebogens zur Erfassung des subjektiven Behandlungskonzepts von Rehabilitanden [Development of a Questionnaire to Assess Treatment Representations in Rehabilitation Patients]. Die Rehabilitation, 48(06), 345-353. https://doi.org/ 10.1055/s-0029-1234052

Glattacker, M., Heyduck, K., \& Meffert, C. (2012). Illness beliefs, treatment beliefs and information needs as starting points for patient information - Evaluation of an intervention for patients with chronic back pain. Patient Education and Counseling, 86(3), 378-389. https://doi.org/10.1016/j.pec.2011.05.028

Glattacker, M., Heyduck, K., \& Meffert, C. (2013). Illness beliefs and treatment beliefs as predictors of short-term and medium-term outcome in chronic back pain. Journal of Rehabilitation Medicine, 45(3), 268-276. https://doi.org/10.2340/16501977-1104

Glattacker, M., Heyduck, K., \& Meffert, C. (2013). Illness beliefs and treatment beliefs as predictors of short and middle term outcome in depression. Journal of Health Psychology, 18(1), 139-152. https://doi.org/10.1177/1359105311433907

Goulding, L., Furze, G., \& Birks, Y. (2010). Randomized controlled trials of interventions to change maladaptive illness beliefs in people with coronary heart disease: Systematic review. Journal of Advanced Nursing, 66(5), 946-961. https://doi.org/10.1111/ j.1365-2648.2010.05306.x

Grothaus, F. J., Birkner, N., Kutschmann, M., Lüken, F., \& Veit, C. (2014). Datenauswertung zur Qualitätssicherung in der medizinischen Rehabilitation nach \$299 Abs. 3 SGB V und verbundene Unterstützungsleistungen - Gesamtbericht zum ersten Durchlauf 2012-2014 [Data evaluation for quality assurance in medical rehabilitation according to \$299 para. 3 SGB V and associated support services - overall report on the first run 2012-2014]. 
https://qs-reha.de/media/dokumente/archiv/01_Gesamtbericht_ QS-Reha_2012_2014.pdf

Guest, G., Bunce, A., \& Johnson, L. (2006). How many interviews are enough? An experiment with data saturation and variability. Field Methods, 18(1), 59-82. https://doi.org/10.1177/ $1525822 \times 05279903$

Hafen, K., Jastrebow, J., Nübling, R., \& Bengel, J. (2001). Entwicklung eines Patientenfragebogens zur Erfassung der Reha-Motivation (PAREMO) [Development of a Patient Questionnaire for Assessment of Rehabilitation Motivation (PAREMO)]. Die Rehabilitation, 40(1), 3-11. https://doi.org/10.1055/ s-2001-12136

Hagger, M. S., Koch, S., Chatzisarantis, N. L. D., \& Orbell, S. (2017). The common sense model of self-regulation: Metaanalysis and test of a process model. Psychological Bulletin, 143(11), 1117-1154. https://doi.org/10.1037/bul0000118

Hagger, M. S., \& Orbell, S. (2021). The common sense model of illness self-regulation: a conceptual review and proposed extended model. Health Psychology Review. Advance online publication. https://doi.org/10.1080/17437199.2021. 1878050

Heyduck, K., Glattacker, M., \& Meffert, C. (2011). Rehabilitation aus Patientensicht - Eine qualitative Analyse der subjektiven Behandlungskonzepte von Patienten in der stationären orthopädischen und psychosomatischen Rehabilitation [Rehabilitation from the patient perspective - A qualitative analysis of the treatment beliefs of patients in inpatient orthopedic and psychosomatic rehabilitation]. Die Rehabilitation, 50(04), 232-243. https://doi.org/10.1055/s-0030-1268000

Hibbard, J. H., \& Greene, J. (2013). What the evidence shows about patient activation: Better health outcomes and care experiences; fewer data on costs. Health Affairs, 32(2), 207-214. https://doi.org/10.1377/hlthaff.2012.1061

Horne, R. (1999). Patients' beliefs about treatment: the hidden determinant of treatment outcome? Journal of Psychosomatic Research, 47(6), 491-495.

Horne, R., Chapman, S. C. E., Parham, R., Freemantle, N., Forbes, A., \& Cooper, V. (2013). Understanding patients' adherence-related beliefs about medicines prescribed for long-term conditions: A meta-analytic review of the Necessity-Concerns Framework. PLoS One, 8(12), Article e80633. https://doi.org/10.1371/journal. pone.0080633

Horne, R., \& Weinman, J. (2002). Self-regulation and Selfmanagement in Asthma: Exploring The Role of Illness Perceptions and Treatment Beliefs in Explaining Non-adherence to Preventer Medication. Psychology \& Health, 17(1), 17-32. https://doi.org/10.1080/08870440290001502

Horne, R., Weinman, J., \& Hankins, M. (1999). The beliefs about medicines questionnaire: The development and evaluation of a new method for assessing the cognitive representation of medication. Psychology \& Health, 14(1), 1-24. https://doi.org/ 10.1080/08870449908407311

Köllner, V. (2014). Psychosomatische Rehabilitation [Psychosomatic rehabilitation]. Psychotherapeut, 59(6), 485-502. https:// doi.org/10.1007/s00278-014-1085-x

Laferton, J. A., Kube, T., Salzmann, S., Auer, C. J., \& SheddenMora, M. C. (2017). Patients' expectations regarding medical treatment: A critical review of concepts and their assessment. Frontiers in Psychology, 8, Article 233. https://doi.org/10.3389/ fpsyg.2017.00233

Lequerica, A. H., Donnell, C. S., \& Tate, D. G. (2009). Patient engagement in rehabilitation therapy: physical and occupational therapist impressions. Disability and Rehabilitation, 31(9), 753-760. https://doi.org/10.1080/09638280802309095

Leventhal, H., Brissette, I., \& Leventhal, E. A. (2003). The commonsense model of self-regulation of health and illness. In L. D.
Cameron \& H. Leventhal (Eds.), The self-regulation of health and illness behaviour (pp. 42-65). Routledge.

Linden, M. (2014). Psychosomatic Inpatient Rehabilitation: The German Model. Psychotherapy and Psychosomatics, 83(4), 205-212. https://doi.org/10.1159/000358852

Maddux, J. E. (1999). Expectancies and the social-cognitive perspective: Basic principles, processes, and variables. In I. Kirsch (Ed.), How expectancies shape experience (pp. 17-39). American Psychological Association. https://doi.org/10.1037/ 10332-001

Manber, R., Chambers, A. S., Hitt, S. K., McGahuey, C., Delgado, P., \& Allen, J. J. B. (2003). Patients' perception of their depressive illness. Journal of Psychiatric Research, 37(4), 335-343.

Mayring, P. (2000). Qualitative Inhaltsanalyse. Grundlagen und Techniken [Qualitative content analysis. Basics and techniques] (7th ed.). Deutscher Studienverlag.

Muthny, F. A., Fiedler, R. G., Richter, M., Schweidtmann, W., \& Wiedebusch, S. (2006). Reha-bezogene Kognitionen (REHAKOG): Vorsätze, Selbstwirksamkeitserwartungen und Befürchtungen [Rehab-related cognitions (REHAKOG): Intentions, self-efficacy and concerns]. In R. Nübling, F. A. Muthny, \& J. Bengel (Eds.), Reha-Motivation und Behandlungserwartung (pp. 179-194). Huber.

Nübling, R., Schulz, H., Juergen, S., \& Bassler, M. (2019, March) Outcome of psychosomatic rehabilitation in Germany - Overview of 30 years of rehabilitation/health services research. Paper presented at the 15th Congress of the European Forum for Research in Rehabilitation, Berlin.

Oettingen, G. (2012). Future thought and behaviour change. European Review of Social Psychology, 23(1), 1-63. https:// doi.org/10.1080/10463283.2011.643698

Paar, G., \& Grohmann, S. (2008). Stationäre psychosomatische Rehabilitation [Inpatient Psychosomatic Rehabilitation]. In G. Schmid-Ott, S. Wiegand-Grefe, C. Jacobi, G. Paar, R. Meermann, \& F. Lamprecht (Eds.), Rehabilitation in der Psychosomatik (pp. 55-74). Schattauer GmbH.

Reuter, L., Bengel, J., \& Scheidt, C. E. (2014). Therapie-NonResponse in der psychosomatischen Krankenhausbehandlung und Rehabilitation - Eine systematische Übersicht [Nonresponse to therapy in acute and rehabilitative psychosomatic inpatient care - A systematic review]. Zeitschrift für Psychosomatische Medizin und Psychotherapie, 60(2), 121-145. https://doi.org/10.13109/zptm.2014.60.2.121

Richter, M., Schmid-Ott, G., \& Muthny, F. A. (2010). Patientenzufriedenheit in der psychosomatischen Rehabilitation [Patient satisfaction in psychosomatic rehabilitation]. Nervenheilkunde, 29(06), 386-392. https://doi.org/10.1055/s-0038-1628782

Schwarzer, R. (1994). Optimism, Vulnerability, and self-beliefs as health-related cognitions: A systematic overview. Psychology \& Health, 9(3), 161-180. https://doi.org/10.1080/ 08870449408407475

Steffanowski, A., Löschmann, C., Schmidt, J., Wittmann, W. W., \& Nübling, R. (2007). Meta-Analyse der Effekte stationärer psychosomatischer Rehabilitation (Mesta-Studie) [Meta-analysis of the effects of inpatient psychosomatic rehabilitation (Mesta study)]. Huber.

Tiggelman, D., van de Ven, M. O. M., van Schayck, O. C. P., Kleinjan, M., \& Engels, R. C. M. E. (2014). The Common Sense Model in early adolescents with asthma: Longitudinal relations between illness perceptions, asthma control and emotional problems mediated by coping. Journal of Psychosomatic Research, 77(4), 309-315. https://doi.org/10.1016/j.jpsychores.2014.07.010

Tong, A., Sainsbury, P., \& Craig, J. (2007). Consolidated criteria for reporting qualitative research (COREQ): A 32-item checklist for interviews and focus groups. International Journal for Quality in Health Care, 19(6), 349-357. https://doi.org/10.1093/intqho/ mzm042 
van Erp, S. J. H., Brakenhoff, L. K. M. P., Vollmann, M., van der Heijde, D., Veenendaal, R. A., Fidder, H. H., Hommes, D. W., Kaptein, A. A., e Jong, A. E., \& Scharloo, M. (2017). Illness perceptions and outcomes in patients with inflammatory bowel disease: Is coping a mediator? International Journal of Behavioral Medicine, 24(2), 205-214. https://doi.org/10.1007/ s12529-016-9599-y

VERBI Software. (2017). MAXQDA 2018. https://www.maxqda.com

Von Wahlert, J., \& Mestel, R. (2008). Kriterien zur Indikation psychosomatischer Rehabilitation und Abgrenzung zur kurativen Psychotherapie [Criteria for the indication of psychosomatic rehabilitation and distinction from curative psychotherapy]. In G. Schmid-Ott, S. Wiegand-Grefe, C. Jacobi, G. Paar, R. Meermann, \& F. Lamprecht (Eds.), Rehabilitation in der Psychosomatik (pp. 255-266). Schattauer GmbH.

Yardley, L., Sharples, K., Beech, S., \& Lewith, G. (2001). Developing a dynamic model of treatment perceptions. Journal of Health Psychology, 6(3), 269-282. https://doi.org/10.1177/ 135910530100600301

\section{History}

Received March 20, 2020

Revision received March 21, 2021

Accepted April 14, 2021

Published online August 2, 2021

\section{Acknowledgments}

The authors are responsible for the content of the article. We would further like to thank Miss Andrea Feigel for her proofreading.

\section{Conflict of Interest}

Matthias Rudolph and Matthias Stapel as employees of the German Federal Pension Insurance Rhinland Palatine, helped conceptualize the study and supported the recruitment of participants, but were not further engaged in the analysis of the data. Rieka von der Warth, Anne Nau, Jürgen Bengel, and Manuela Glattacker declare that they have no conflict of interest.

\section{Publication Ethics}

Ethical approval was granted by the Ethics Committee at the University of Freiburg (Approval Number: 231/18) and was registered in the German Clinical Trial Register (DRKS00014830).

\section{Funding}

This study was funded by the German Federal Pension Insurance Rhineland Palatinate [432 - 01 - 3351]. Open access publication enabled by University of Freiburg.

\section{ORCID}

Rieka von der Warth

(D) https://orcid.org/0000-0003-2445-8019

\section{Rieka von der Warth}

Section of Health Care Research and Rehabilitation Research Medical Center

University of Freiburg

Hugstetter Str. 49

79106 Freiburg

Germany

rieka.warth@uniklinik-freiburg.de 